\title{
SPEAKCODE: UMA FERRAMENTA DE ACESSIBILIDADE PARA PESSOAS COM DEFICIÊNCIA VISUAL
}

\author{
Marcio Carneiro Brito Pache ${ }^{*}$, Aline Bezerra da Costa, Sandro Rodrigues Souza, Lucas Hermann Negri \\ *E-mail: marcio.pache@ifms.edu.br \\ Instituto Federal de Educação, Ciência e Tecnologia do Mato Grosso do Sul \\ DOI: $10.15628 /$ rbept.2020.7934
}

Artigo submetido em: nov/2018 e aceito em mar/2020

\begin{abstract}
RESUMO
Este artigo descreve o desenvolvimento do aplicativo SpeakCode, voltado para a leitura e transcrição do conteúdo de Códigos QR em áudio. O aplicativo, implementado para dispositivos móveis, possibilita que usuários com deficiência visual possam identificar objetos previamente marcados, facilitando a realização de tarefas cotidianas e profissionais. $O$ aplicativo foi validado através de testes com usuários especialistas e um usuário final (pessoa com deficiência visual), obtendo uma avaliação positiva e a sugestão da expansão e implantação do projeto em maior escala.
\end{abstract}

Palavras-chave: App, Acessibilidade, Deficiente visual, Android

\section{SPEAKCODE: AN ACCESSIBILITY TOOL FOR PEOPLE WITH VISUAL IMPAIRMENT}

\begin{abstract}
This article describes the development of the SpeakCode application, aimed at reading and transcribing the contents of QR Codes in audio. The application, implemented for mobile devices, enables visually impaired users to identify previously marked objects, making it easier to perform everyday and professional tasks. The application was validated through testing with expert users and a final user (visually impaired person), obtaining a positive evaluation and suggestion of expanding and deploying the project on a larger scale.

Keywords: App, Accessibility, Visually-impaired, Android.
\end{abstract}




\section{INTRODUÇÃO}

Trata-se de um trabalho de divulgação de um aplicativo para dispositivos móveis, integrando a tecnologia dos smartphones, através do uso da câmera do aparelho. Para isso, de maneira a facilitar tanto a escrita, quanto a leitura da informação, bem como o processo de interação Homem-Computador, identificou-se a possibilidade de se utilizar códigos QR transformando os dados textuais em mensagens de áudio, compreensíveis por pessoas com deficiência visual.

Através desta aplicação, por meio de princípios da Tecnologia Assistiva, que de acordo com a Fundação Dorina Nowill (2017), visa "identificar recursos e serviços que contribuem para proporcionar habilidades funcionais de pessoas com deficiência"; buscou-se facilitar a inclusão de pessoas com deficiência visual, integrando a tecnologia em seu cotidiano, de maneira a permitir melhores condições de acessibilidade.

Este artigo objetiva a divulgação científica do aplicativo através do uso de tecnologias assistivas para auxiliar pessoas com deficiência visual na identificação de objetos. Devido à vasta capacidade tecnológica proporcionada pelos smartphones espera-se atingir esse contingente através da criação de ferramentas que proporcionem uma usabilidade com fim prático na resolução de problemas destes usuários.

Para tanto, alguns objetivos específicos foram estruturados dentre os quais: Desenvolver uma aplicação que auxilie deficientes visuais, garantindo maior acessibilidade através do uso da tecnologia; Realizar a leitura de $Q R$ Codes utilizando a câmera de aparelhos smartphones; Transcrever o conteúdo escaneado em áudio.

Justifica-se este trabalho de pesquisa aplicada pelos dados registrados pela Organização Mundial da Saúde - OMS, através de publicação das Nações Unidas no Brasil (2013), mostra que existem no mundo aproximadamente 39 milhões de cegos e 246 milhões de pessoas com baixa visão.

Villela (2015) apresenta que um levantamento divulgado em 2015 pelo Instituto Brasileiro de Geografia e Estatística (IBGE) juntamente com o Ministério da Saúde apontou que $6,2 \%$ da população brasileira têm algum tipo de deficiência. Neste levantamento foram considerados quatro tipos de deficiências: auditiva, visual, física e intelectual.

Dentre os tipos de deficiência pesquisados, a visual é a mais representativa e atinge $3,6 \%$ dos brasileiros, sendo mais comum entre as pessoas com mais de 60 anos (11,5\%). O grau intenso ou muito intenso da limitação impossibilita $16 \%$ dos deficientes visuais de realizarem atividades habituais como ir à escola, trabalhar e brincar. (VILLELA, 2015)

Existem atualmente vários tipos de sistemas que buscam garantir a acessibilidade de pessoas com algum tipo de necessidade especial, esses meios são desenvolvidos através da chamada tecnologia assistiva, composta especificamente por aplicativos, escrita em braile, piso tátil, entre outros. Entretanto são alternativas que ainda apresentam um custo de aquisição muito elevado, principalmente no Brasil. Logo, torna- 
se relevante criar e desenvolver tecnologias a fim de proporcionar melhores condições de vida para essas pessoas.

\section{REVISÃO TEÓRICA}

Com o intuito de obter um melhor entendimento, foram pesquisados alguns conceitos básicos para esclarecer melhor os principais termos a serem utilizados no decorrer do trabalho. Além disso, tomamos por base dados históricos e quantitativos sobre as tecnologias a serem empregadas bem como acerca das prerrogativas que envolvem o deficiente visual, tais como as Leis que regem sobre o tema Acessibilidade e Deficiência.

De maneira a subsidiar o trabalho tomamos por base os estudos voltados à Engenharia de Software e Programação para Dispositivos Móveis, sempre voltando ao alinhamento com a tecnologia dos $Q R$ Codes.

Liao \& Lee, (2010) relatam que na década de 1960, quando o Japão atingiu seu apogeu econômico, os supermercados e as lojas começaram a vender uma grande variedade de commodities de alimentos e de roupas para seus clientes. Porém os preços desses produtos eram inseridos manualmente, fazendo que muitos atendentes de caixas sofressem de dormência no pulso ou desenvolvessem a síndrome do túnel do carpo ${ }^{1}$.

Pensando nisso, os japoneses desenvolveram o sistema $\mathrm{POS}^{2}$, no qual o preço de um item de mercadoria é exibido na caixa registradora automaticamente quando o código de barras do item for escaneado através de um sensor óptico e as informações desse item são enviadas para um computador.

Conforme a tecnologia do código de barras se espalhou, suas limitações também se tornaram evidentes. O mais interessante foi o fato de que um código de barras só poderia conter 20 caracteres alfanuméricos, ou seja, uma combinação de números e letras.

Dessa maneira, Hara (2014) relata que os usuários dos códigos de barras, entraram em contato com a Denso Wave Incorporated (então uma divisão da Denso Corporation) desenvolvedora dos leitores de código de barras naquela época, para perguntar se era possível desenvolver códigos de barras que poderiam conter mais informações, dizendo: "Nós gostaríamos de codificar Kanji e Kana, bem como alfanuméricos", (HARA, 2014).

Incentivados por esses pedidos entusiasmados, uma equipe de desenvolvimento da Denso Wave, formada pelos cientistas Masahiro Hara e Takayuki Nagaya e depois agregou Motoaki Watanabe, Yuji Uchiyama e Tadao Nojiri, embarcou no desenvolvimento de um novo código bidimensional, o que veio a se tornar uma especificação internacional ISO/IEC 18004:2006 (ISO, 2006).

\footnotetext{
${ }^{1}$ Síndrome do Tunel de Carpo: é causada pela compressão do nervo mediano que passa por um canal estreito no punho chamado de Túnel do Carpo.

2 POS: é a sigla usada para designar Point of Sale. Trata-se do ponto de venda, isto é, o local onde o cliente paga as suas compras.
} 
De acordo com Liao e Lee (2010) o QR Code foi lançado em 1994 pela empresa Denso Wave Incorporated, e é apresentado como uma evolução do Código de Barras. QR é a abreviação de "Quick Response", o que em Português significa "resposta rápida", portanto consiste em um código de leitura rápida. Essa leitura pode ser realizada por aplicativos que podem ser facilmente instalados em aparelhos que possuem câmera fotográfica e sistemas operacionais Android ou IOS. O QR Code pode codificar: endereços de e-mail, números de telefones, imagens de produtos, vídeos, mensagem ou anotações textuais, podendo também, incluir um evento no calendário digital, um endereço em um mapa, entre outras coisas.

Segundo Denso Wave (2019) o " $Q R$ Code é uma representação binária de dados em um código de barra bidimensional" presente em diversas coisas, como por exemplo, embalagens de produtos e diversificados formatos de mídias e publicidade.

Martins (2009) afirma que ao longo dos anos, os códigos bidimensionais ou 2D foram evoluindo para se adequar melhor a necessidade de cada usuário. $O$ autor relata ainda que o $Q R$ Code é composto "por matrizes com células de altura e largura de comprimento fixo e completamente preenchidos com um valor de cor ou tom único" intercalando espaços pretos e brancos. Na Figura 1 que está logo abaixo vemos 0 exemplo de um QR Code.

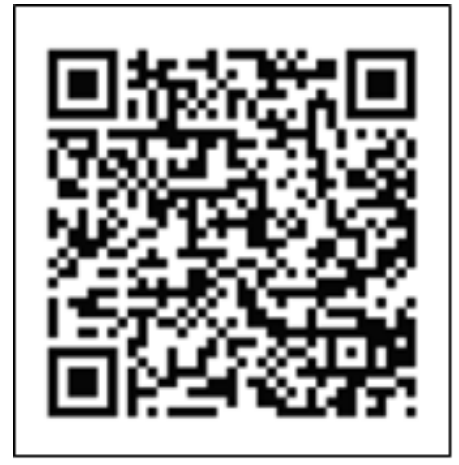

Figura 1: Exemplo de um QR Code.

O uso de $Q R$ Code é livre de qualquer licença e os direitos de patente ainda pertencem à empresa Denso Wave Incorporated.

Para Kimura (2014), O QR Code "tem sido integrado ao conteúdo hipermidiático como um texto cultural em formatos, capaz de modelizar a comunicação em diferentes tipos de linguagens, uma vez que funciona como um atalho para aparelhos móveis".

Existem cinco tipos de $Q R$ Code, sendo eles: $Q R$ Code Modelo 1 e Modelo 2, Micro $Q R$ Code, $i Q R$ Code, Secure-QR Code (SQRC) e Frame QR (DENSO WAVE, 2019).

De acordo com Soon (2008), o código permite uma leitura dos dados em qualquer direção entre os $360^{\circ}$, através do padrão de detecção da posição localizada nos três cantos de cada símbolo $Q R$ Code. Ainda de acordo com o autor, a leitura legível em todas as direções proporciona uma leitura mais precisa e rápida dos dados. 
As características da tecnologia dos $Q R$ Codes se mostraram bastante propícias para o desenvolvimento do trabalho, haja vista que a facilidade de leitura e a capacidade de conteúdo, dentre outras, compreendem exatamente as necessidades envoltas no cenário do deficiente visual, integrando-o por meio de uma tecnologia acessível.

O termo acessibilidade trouxe para os dias atuais, uma preocupação constante em atender pessoas com deficiências (físicas e mentais), proporcionando-as condições de interação igualitária diante das mesmas circunstâncias vivenciadas em sociedade. Logo, faz necessário elucidar sobre a definição deste conceito:

Pessoas com deficiência são aquelas que têm impedimentos de longo prazo de natureza física, mental, intelectual ou sensorial, os quais, em interação com diversas barreiras, podem obstruir sua participação plena e efetiva na sociedade em igualdades de condições com as demais pessoas. (BRASIL, 2009)

Segundo decreto oㅜ 3.298, de 20 de dezembro de 1999, considera-se deficiência "toda perda ou anomalia de uma estrutura ou função psicológica, fisiológica ou anatômica que gere incapacidade para o desempenho de atividade, dentro do padrão considerado normal para o ser humano".

A lei $n^{\circ} 10.098$, de 19 de dezembro de 2000, traz importantes conceitos que permitem direcionar os pensamentos acerca do assunto em dois incisos:

I - Acessibilidade: possibilidade e condição de alcance para utilização, com segurança e autonomia, de espaços, mobiliários, equipamentos urbanos, edificações, transportes, informação e comunicação, inclusive seus sistemas e tecnologias, bem como de outros serviços e instalações abertos ao público, de uso público ou privados de uso coletivo, tanto na zona urbana como na rural, por pessoa com deficiência ou com mobilidade reduzida. (BRASIL, 2000).

II - Barreiras: qualquer entrave, obstáculo, atitude ou comportamento que limite ou impeça a participação social da pessoa, bem como o gozo, a fruição e o exercício de seus direitos à acessibilidade, à liberdade de movimento e de expressão, à comunicação, ao acesso à informação, à compreensão, à circulação com segurança, entre outros. (BRASIL, 2000).

Segundo decreto oㅜ 6.949, de 25 de agosto de 2009, que "promulga a Convenção Internacional sobre os Direitos das Pessoas com Deficiência e seu Protocolo Facultativo, assinados em Nova York, em 30 de março de 2007", o propósito das discussões é "promover, proteger e assegurar o exercício pleno e equitativo de todos os direitos humanos e liberdades fundamentais por todas as pessoas com deficiência e promover 0 respeito pela sua dignidade inerente". Dessa forma, o documento traz normativas que tratam do processo de integração da pessoa com deficiência, garantindo a ela 0 exercício dos seus direitos. Sabe-se, entretanto, que 0 direito às liberdades fundamentais das pessoas com deficiências é muitas vezes limitado, até mesmo em situações práticas e rotineiras.

Pode-se perceber nas normativas, que ao mesmo tempo em que se assegura (legalmente) o acesso aos direitos às pessoas com deficiência, se afirma também, a concreta existência de barreiras, que dificultam essa garantia. 
A deficiência visual engloba o universo de pessoas cegas e com baixa visão (ou visão subnormal) e é decorrente de problemas de diferentes ordens, a saber: congênita, adquirida, genética ou degenerativa. Dentre as principais causas da deficiência visual, encontram-se: a retinopatia da prematuridade, que consiste na imaturidade da retina decorrente de partos prematuros ou de excesso de oxigênio na incubadora; a catarata congênita, causada pela ocorrência de rubéola ou outras infecções intrauterinas; o glaucoma congênito, doença que pode ser de ordem genética, ou fruto de infecções, dentre outros fatores (MONTEIRO, 2012 apud MAIOLA; SILVEIRA, 2009).

Uma análise da OMS disponível através das Nações Unidas no Brasil (2013) retrata que são cerca de 285 milhões de deficientes visuais, sendo 39 milhões de cegos e 246 milhões de baixa visão. O número expressivo de pessoas com deficiência visual evidencia o quanto os direitos básicos das pessoas com deficiência estão sendo poucos exercidos, realidade esta que precisa ser revista e destacada.

No entanto, diversas ações, dentre as quais pesquisas científicas e iniciativas de representação em entidades (órgãos e classes), vêm sendo realizadas com o propósito de efetivar esses direitos. Uma forma crescente de intervenção nesta realidade ocorre através do uso da tecnologia, objetivando diminuir a exclusão dos deficientes visuais por meio de iniciativas que minimizem a sua incapacidade ou possibilitem meios alternativos de exercer seu direito.

É fato que a Tecnologia Assistiva desempenha um papel fundamental para os deficientes visuais permitindo-lhes desempenhar tarefas que seriam praticamente impossíveis sem o auxílio apropriado. A ausência deste apoio impõe restrições quase intransponíveis ao acesso na inclusão digital, além de impedir a inclusão destes indivíduos na era da informação e comunicação. (CAMPÊLO et al., 2011, p. 112).

As inovações tecnológicas trouxeram grandes contribuições para muitas áreas, expandindo o acesso às informações e a comunicação de forma global. Assim, essas tecnologias conhecidas como TICs - Tecnologias de Informação e Comunicação, também abrangeram as Tecnologias Assistivas, para atender a população com necessidades especiais, promovendo assim, a inclusão social, digital e educacional.

\section{METODOLOGIA}

Os procedimentos foram distribuídos em várias etapas permitindo assim 0 acompanhamento e gestão do processo de desenvolvimento. A primeira etapa do projeto contemplou a busca de materiais bibliográficos e pesquisas na internet relativas ao tema proposto. A segunda etapa esteve relacionada à seleção dos materiais, leitura e fichamento dos textos.

Realizado o conhecimento do universo dessa pesquisa, inicia-se, então, a terceira etapa que consiste no desenvolvimento da aplicação concomitantemente à elaboração da documentação do projeto. Segundo Engholm (2010), o processo de Desenvolvimento de Software incluiu as seguintes etapas:

1. Levantamento de Requisitos; 
2. Análise;

3. Projeto (desenho);

4. Implementação;

5. Testes;

6. Implantação.

O modelo de Ciclo de Vida definido para nortear o processo de desenvolvimento é o modelo de prototipação que, "permite que todo o sistema, ou parte dele, seja construído rapidamente para que questões sejam entendidas ou esclarecidas" conforme descrito por (PFLEEGER, 2007, pag. 42).

O projeto foi desenvolvido utilizando a Linguagem de Modelagem Unificada UML, através da Modalidade Orientada a Objetos, que de acordo com ENGHOLM, (2010, pag. 57) "refere-se à organização mais alta de um projeto de software, podendo ser desfragmentada em fases intermediárias que, por sua vez, podem ser decompostas em workflows, e estes em atividades".

Inicialmente, foi realizado o levantamento de requisitos do projeto, e posteriormente sua análise, de maneira a orientar a definição das funcionalidades da aplicação. Paralelamente ao processo de diagnóstico foi iniciada a criação de um protótipo utilizando a plataforma de desenvolvimento do Applnventor. A Figura 2 mostra o código deste protótipo.

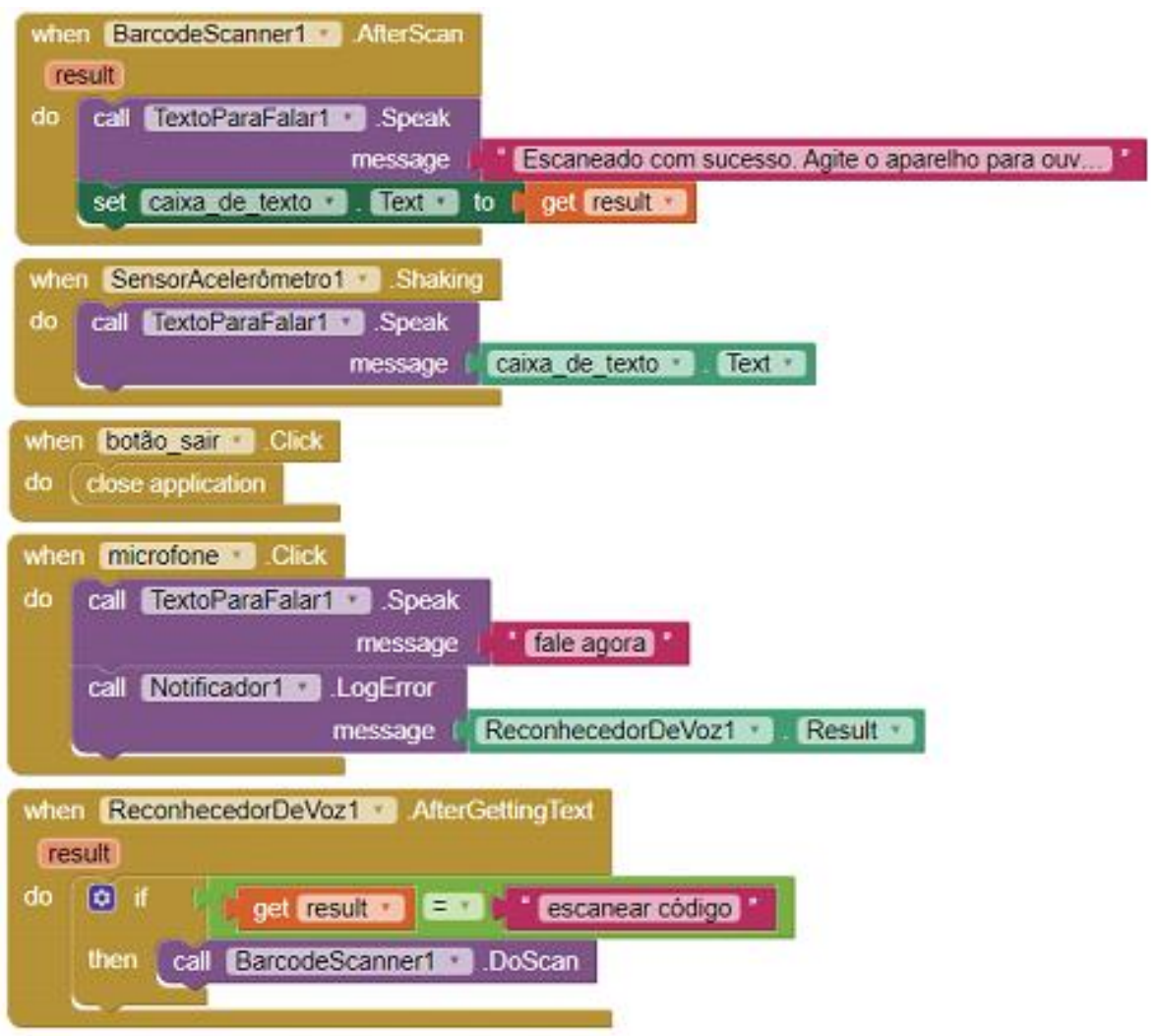

Figura 2 - Código do protótipo no software App Inventor 
Esse tipo de linguagem forneceu os diagramas de modelagem que foram utilizados nos processos do ciclo de desenvolvimento do software. Foram feitos os seguintes Diagramas: Caso de Uso, Componentes e de Atividades. Para a elaboração dos Diagramas foi utilizado o Astah Community, uma ferramenta de modelagem UML (Linguagem de Modelagem Unificada) de software livre.

O Diagrama de Caso de Uso (Figura 3) possibilita a qualquer pessoa interessada na aplicação o entendimento de suas principais funcionalidades sem ter a necessidade de um protótipo experimental.

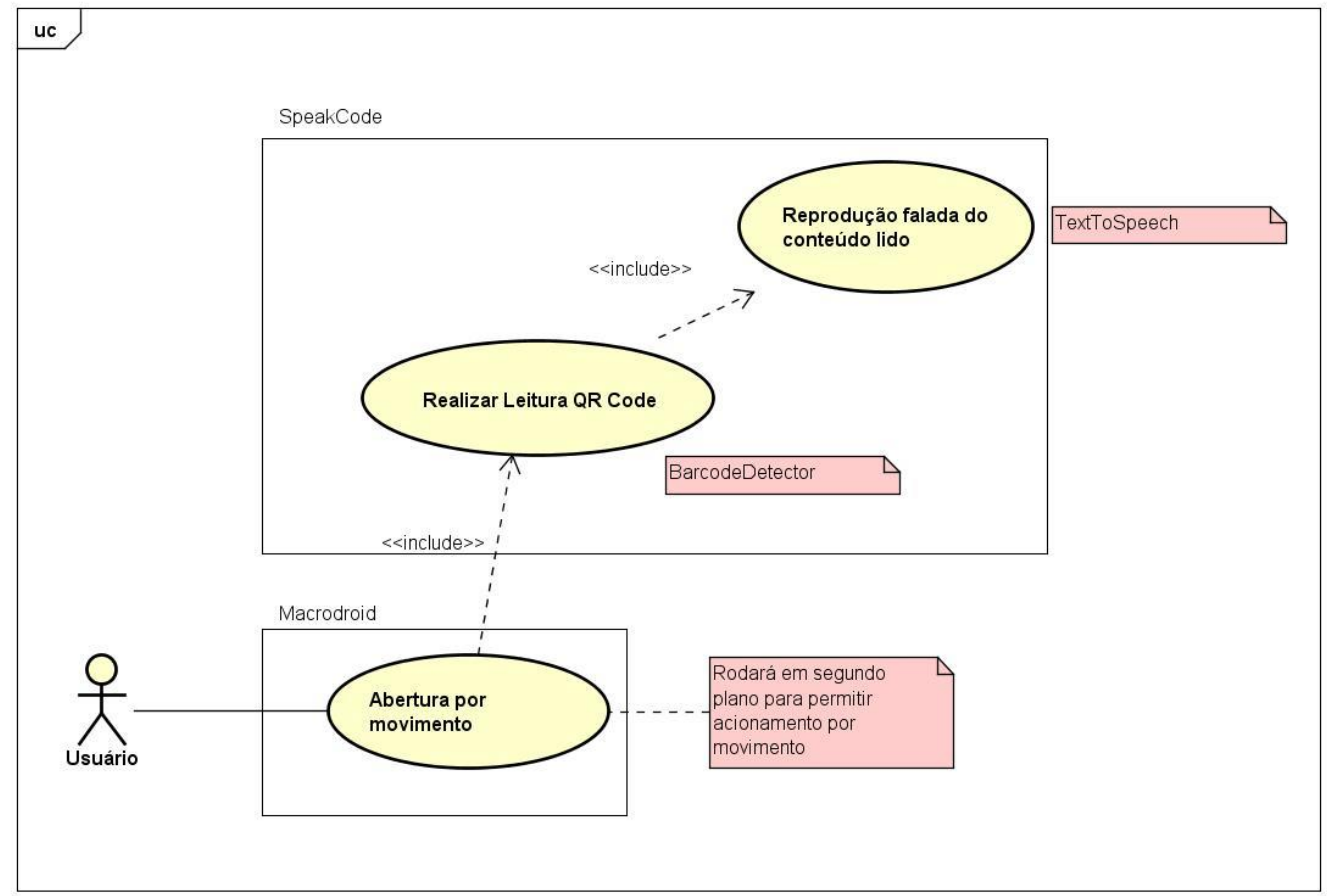

Figura 3 - Diagrama de Caso de Uso.

A Tabela 1 realiza o detalhamento dos casos de uso Realizar Leitura $Q R$ Codes; e Reprodução Falada do Conteúdo Lido.

Tabela 1 - Detalhamento dos casos

\begin{tabular}{|l|l|l|}
\hline Caso de Uso: & Realizar Leitura QR Codes & $\begin{array}{l}\text { Reprodução Falada do Conteúdo } \\
\text { Lido }\end{array}$ \\
\hline Objetivo: & $\begin{array}{l}\text { Realizar a leitura do conteúdo do } Q R \\
\text { Code. }\end{array}$ & $\begin{array}{l}\text { Transcrever o conteúdo lido em } \\
\text { áudio. }\end{array}$ \\
\hline Requisitos: & Escanear a imagem. & Receber conteúdo de texto. \\
\hline Atores: & Usuário Deficiente Visual & Usuário Deficiente Visual \\
\hline
\end{tabular}




\begin{tabular}{|c|c|c|}
\hline Prioridade: & Alta & Alta \\
\hline Pré-condições: & $\begin{array}{l}\text { Abertura do aplicativo - acionamento da } \\
\text { câmera; } \\
\text { Escaneamento da imagem }\end{array}$ & Conversão do conteúdo em texto. \\
\hline $\begin{array}{l}\text { Frequência de } \\
\text { uso: }\end{array}$ & Sempre & Sempre \\
\hline Criticalidade: & - & - \\
\hline $\begin{array}{l}\text { Condição de } \\
\text { Entrada: }\end{array}$ & $\begin{array}{l}\text { Movimento do aparelho; } \\
\text { Escaneamento da imagem. }\end{array}$ & - \\
\hline Fluxo Principal: & $\begin{array}{l}\text { Abertura do Aplicativo por movimento } \\
\text { do aparelho; } \\
\text { Acionamento da Câmera; } \\
\text { Posicionamento da Câmera - } \\
\text { escaneamento da imagem; } \\
\text { Conversão do conteúdo em texto. }\end{array}$ & $\begin{array}{l}\text { Recebimento do conteúdo em texto; } \\
\text { Transcrição do conteúdo em áudio. }\end{array}$ \\
\hline
\end{tabular}

Para um melhor entendimento para a equipe de desenvolvimento o Diagrama de Componentes (Figura 4) foi desenvolvido para representar os principais componentes do sistema.

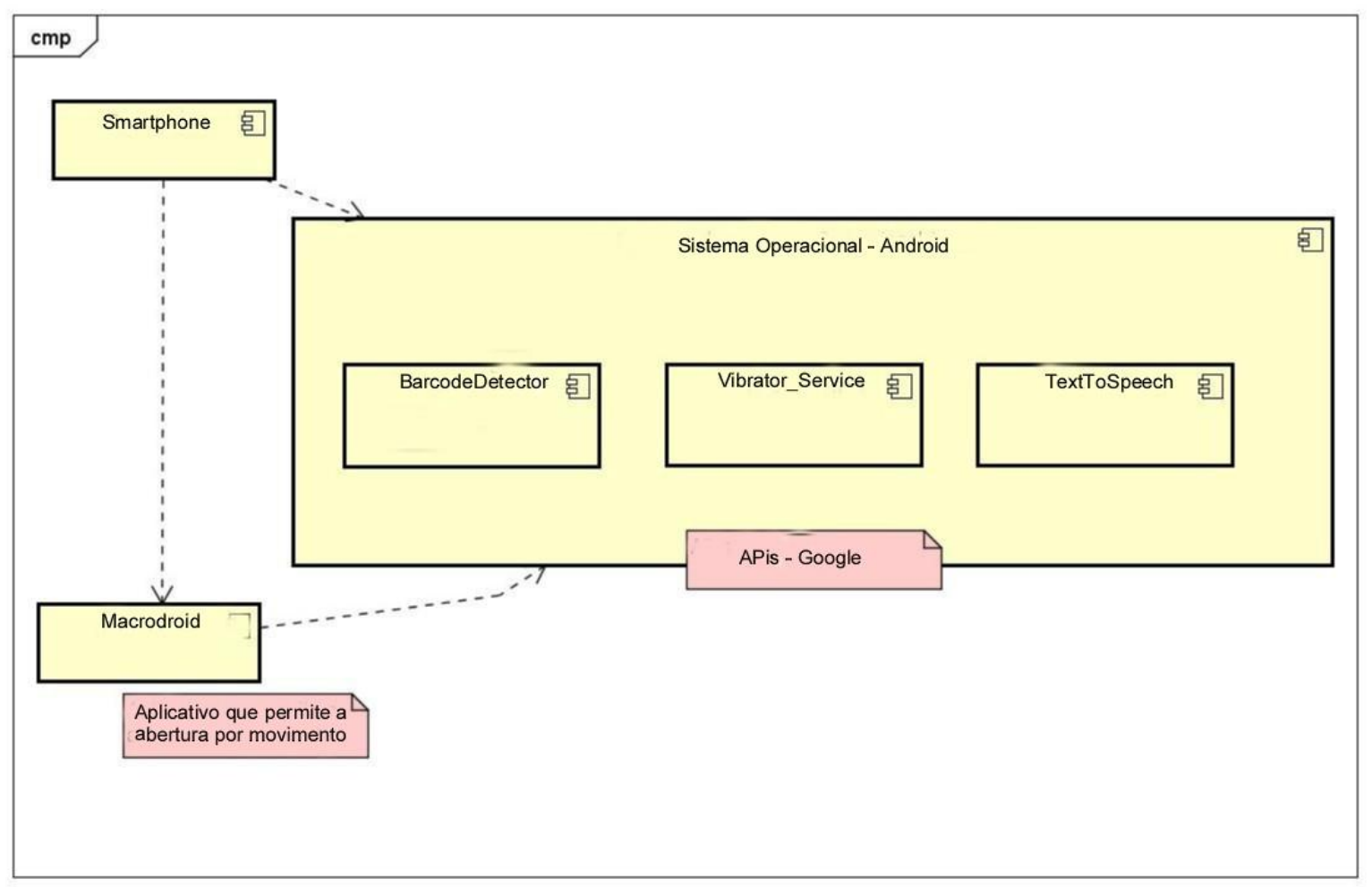

Figura 4 - Diagrama de Componentes. 
Por último, mas não menos importante o Diagrama de Atividades (Figura 5) serve para delimitar o inicio e fim do ciclo de vida das atividades no software.

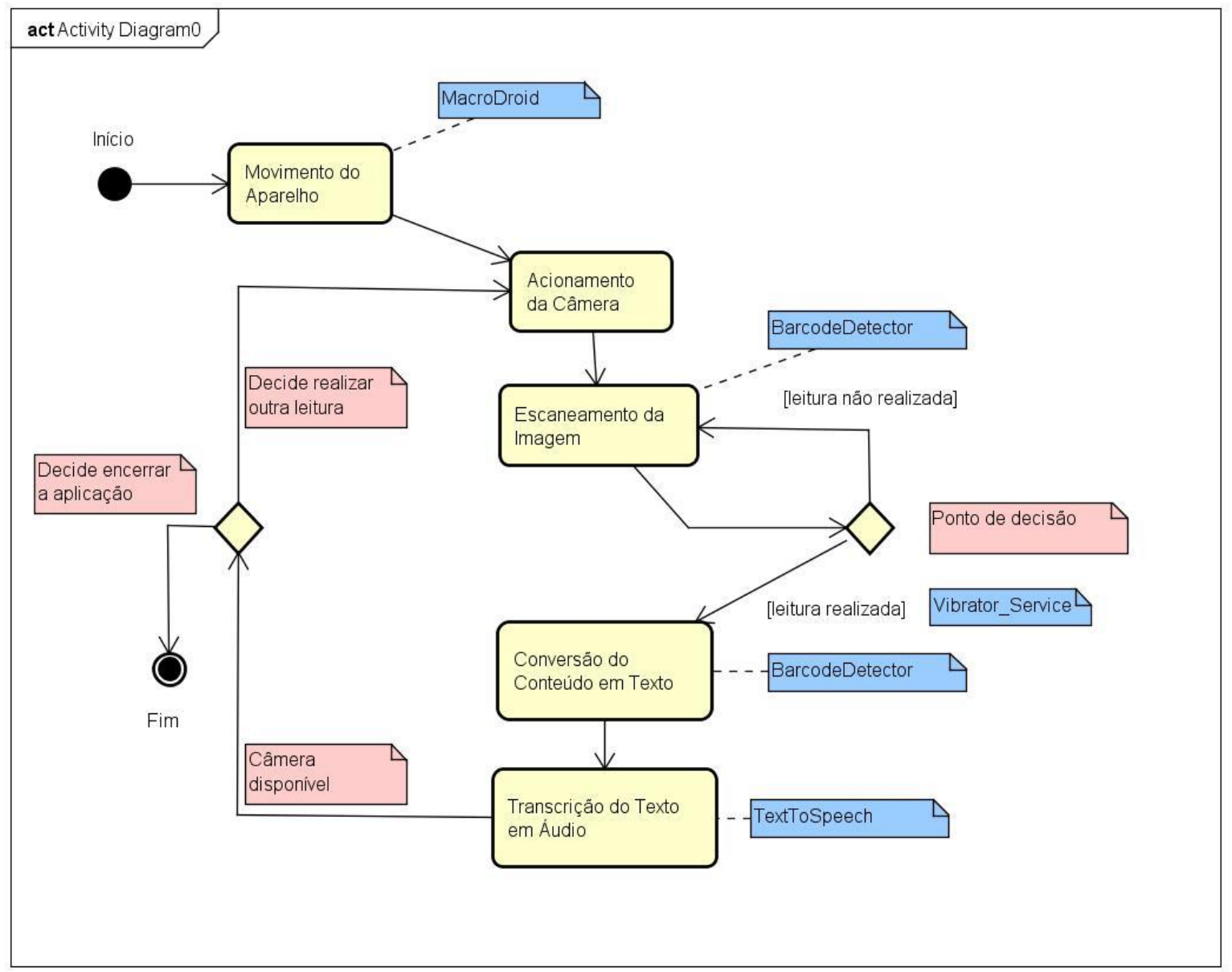

Figura 5 - Diagrama de Atividades.

O desenvolvimento do aplicativo ocorreu em duas vertentes, uma no Applnventor e outra no Android Studio. A princípio não foi possível realizar todas as funcionalidades da aplicação, haja vista que a plataforma Applnventor possui algumas limitações de bibliotecas. Decidiu-se então migrar para a IDE (Ambiente de Desenvolvimento Integrado) Android Studio, uma plataforma profissional, cuja linguagem é baseada em Java e XML, além da utilização de APIs, bibliotecas e frameworks.

Para MENG; STEINHARDT; SCHUBERT (2018), API significa Interface para a Programação de Aplicações (Application Programming Interface), que utilizam de dados ou serviços predefinidos e armazenados em um pacote ou biblioteca de funcionalidades acessíveis para o programador, sem ter a necessidade de recriá-las novamente. As principais APIs utilizadas para o desenvolvimento do SpeakCode foram as APIs da Google Developer, tais como: BarcodeDetector; Vibrator_Service e Speech.tts.TextToSpeech. 


\section{RESULTADOS E DISCUSSÕES}

Após a implementação do protótipo, comportando os requisitos inicialmente levantados e validados, procedeu-se a realização de testes com usuários finais.

O ambiente escolhido para teste foi o de um comércio de produtos artesanais, localizado na cidade de Aquidauana-MS, onde o espaço é organizado por setores, no qual delimitou-se a área do expositor de bebidas e farinhas de frutas. Neste espaço são expostos frascos de bebidas como licores, aguardentes, dentre outras, bem como embalagens de farinhas artesanais de frutas. Essa categoria apresenta produtos de difícil identificação por meio do tato, devido à semelhança dos frascos e embalagens e pelo fato de a diferenciação estar escrita em rótulo simples.

As Figuras 6 a) e 6 b) mostram a interface gráfica do protótipo SpeakCode. Logo que o aplicativo é aberto, é acionada a tela de captura de imagem (a), através da câmera do aparelho e assim que a leitura for realizada é exibido o texto escrito na tela e em áudio (b).

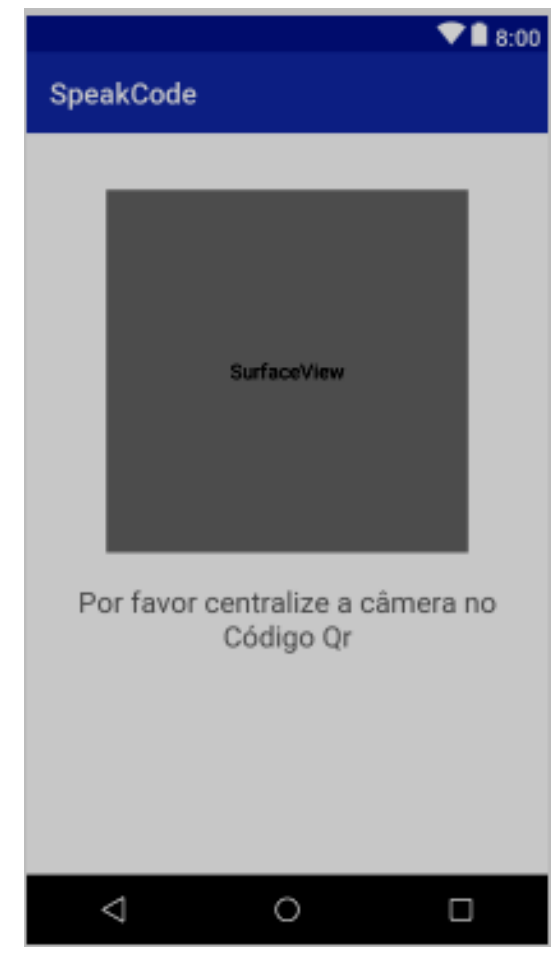

a) Aguardando leitura;

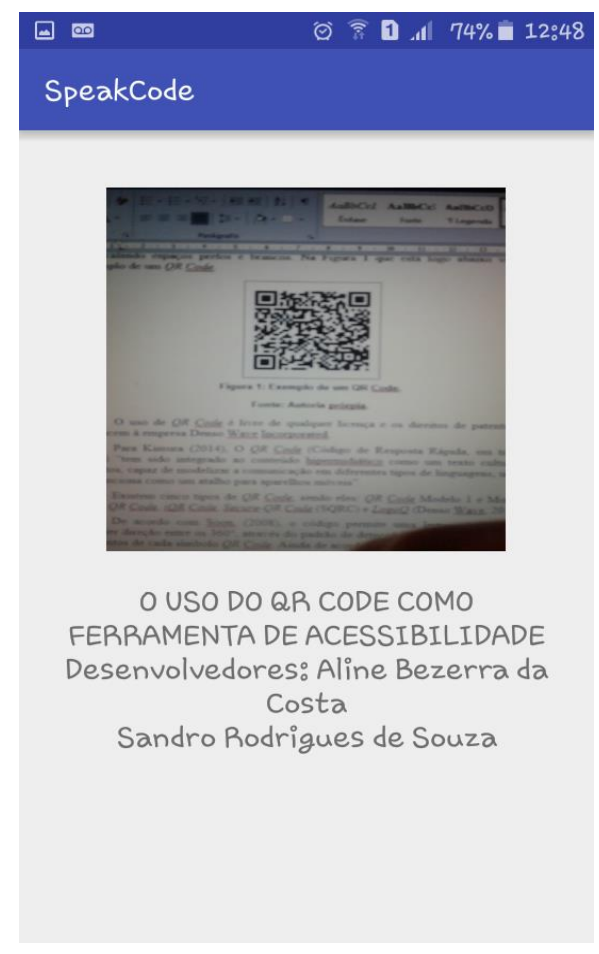

b) Leitura realizada

Figura 6 - Interface Gráfica do Protótipo SpeakCode - a) aguardando leitura; b) leitura realizada.

O propósito do teste era permitir que o usuário identificasse os produtos através do uso do $Q R$ Code fixado nos frascos. O padrão da impressão foi o mesmo em todos os casos, em papel, tamanho e local de fixação diferente do rótulo original, facilitando a localização e identificação do mesmo. A Figura 7 mostra os produtos já com a codificação $Q R$ Code para aplicação dos testes. 
Para prosseguir com a validação do aplicativo foi formatado um Plano de Testes de maneira a verificar o funcionamento da aplicação, para saber o nível de dificuldades e satisfação do usuário. Por fim, a implantação do software no aparelho do usuário.

Os dados obtidos nos testes auxiliaram no aperfeiçoamento do aplicativo e a correção de falhas, o que de acordo com as orientações de Erikson (1986 p. 283-306), esta triangulação é de suma importância para garantir o êxito da investigação, garantindo o suporte necessário às ações de adequação de cada situação.

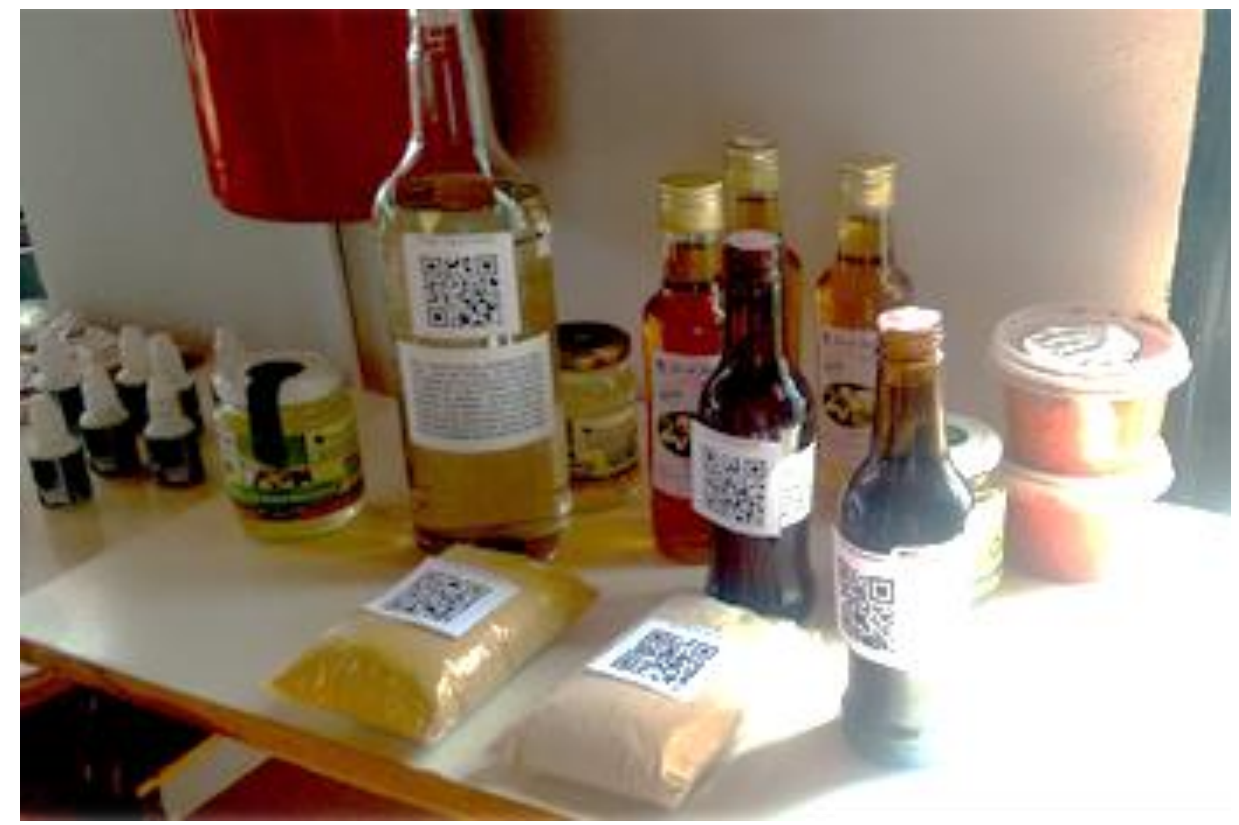

Figura 7: Produtos com QR Code para testes.

\subsection{Plano de Testes}

O Plano de Teste teve por base duas vertentes: teste com usuários técnicos e testes com usuário final, haja vista as limitações destes e a necessidade de disponibilizar a eles algo usual e de acordo com suas necessidades. Sobre o aplicativo foram feitos testes de usabilidade e de validação dos requisitos levantados.

\subsection{Execução do Plano de Testes}

Ao realizar os testes com o usuário final, foi utilizado um aparelho celular da marca Samsung, modelo Galaxy J2, versão Android 5.1.1, ao qual foi instalado o aplicativo juntamente com um software auxiliar chamado de Macrodroid, essa ferramenta permite que o acionamento do aplicativo seja feito através do movimento de chacoalho, eximindo a necessidade de identificação e acionamento do ícone na tela, facilitando assim, a abertura do aplicativo. Para tanto, será necessário que Macrodroid execute em segundo plano ou que tenha alguma tecla programada no aparelho para sua abertura. $O$ detalhamento dos testes está apresentado nas Tabelas 2, 3 e 4. 
A proposta do aplicativo foi delimitada no Teste 1 (Tabela 2) onde pode-se ajustar o tipo de aparelho do usuário e estabelecer as principais funcionalidades, resultando em uma avaliação positiva para o usuário e espera com desejo de realização.

Tabela 2 - Plano de Teste - Teste 1.

\begin{tabular}{|c|c|c|c|c|}
\hline Teste: & Tipo: & ntação & Data: & $9 / 05 / 2018$ \\
\hline Testador: & Usuário final & \multicolumn{2}{|c|}{ Ambiente de Teste: } & Residência \\
\hline Equipamento: & \multicolumn{4}{|l|}{ Desenvolvedores } \\
\hline $\begin{array}{l}\text { Material } \\
\text { impresso: }\end{array}$ & Folha sulfite & \multicolumn{2}{|c|}{ Tipo de impressão: } & Laser \\
\hline Base de análise: & $\begin{array}{l}\text { Folha sulfite fixada na } \\
\text { prancheta }\end{array}$ & \multicolumn{2}{|c|}{ Tamanho do código: } & $10 \mathrm{~cm}^{2}$ \\
\hline Responsáveis: & \multicolumn{4}{|c|}{ Aline Bezerra da Costa e Sandro Rodrigues de Souza } \\
\hline Proposta inicial: & \multicolumn{4}{|c|}{$\begin{array}{l}\text { Apresentação do projeto; Familiarização com a tecnologia aplicada; Avaliação } \\
\text { do uso do aparelho; Descrição das funcionalidades. }\end{array}$} \\
\hline \multirow[t]{2}{*}{ Avaliação: } & \multicolumn{2}{|c|}{ Pontos fortes } & \multicolumn{2}{|l|}{ Pontos fracos } \\
\hline & \multicolumn{2}{|c|}{$\begin{array}{l}\text { - Aceite do projeto; } \\
\text { - Apresentação da tecnologia - } \\
\text { delimitações e usabilidade; } \\
\text { - Disponibilidade do usuário ao } \\
\text { teste; } \\
\text { - Empolgação e Empenho do } \\
\text { usuário; } \\
\text { - Validação e Contribuições do } \\
\text { usuário; }\end{array}$} & \multicolumn{2}{|c|}{$\begin{array}{l}\text { - Dificuldade na delimitação do } \\
\text { escopo da pesquisa; } \\
\text { - Criar altas expectativas ao } \\
\text { usuário; } \\
\text { - Usabilidade do material utilizado - } \\
\text { prancheta e códigos muito grandes; } \\
\text { - Manuseio do aparelho smartphone } \\
\text { pelo usuário; }\end{array}$} \\
\hline Resultado: & \multicolumn{4}{|c|}{$\begin{array}{l}\text { Necessidade de adequação: } \\
\text { - Mecanismo de acionamento da câmera; } \\
\text { - Resposta ao usuário assim que a câmera estiver disponível. }\end{array}$} \\
\hline
\end{tabular}

Para segundo teste (Tabela 3), foi realizada a colagem dos códigos QR nas embalagens dos produtos comercializados e procedeu-se ao escaneamento destes. Verificou-se a influencia de fatores de iluminação ambiente e superfície que contém o código.

Tabela 3 - Plano de Teste - Teste 2.

\begin{tabular}{|c|c|c|c|c|c|}
\hline Teste: & 2 & Tipo: & Aplicação & Data: & $14 / 05 / 2018$ \\
\hline Testador: & \multicolumn{2}{|c|}{ Usuário final } & $\mathrm{Am}$ & Teste: & Comércio \\
\hline Equipamento: & \multicolumn{5}{|c|}{ Desenvolvedores } \\
\hline
\end{tabular}




\begin{tabular}{|c|c|c|c|c|}
\hline $\begin{array}{l}\text { Material } \\
\text { impresso: }\end{array}$ & Folha sulfite & \multicolumn{2}{|c|}{ Tipo de impressão: } & Laser \\
\hline Base de análise: & $\begin{array}{l}\text { Folha sulfite cortada no } \\
\text { formato de etiquetas, sendo } \\
\text { estas fixadas nos produtos: } \\
\text { embalagem de farinha de } \\
\text { frutas e garradas de licor } \\
\text { (vidro) }\end{array}$ & \multicolumn{2}{|c|}{ Tamanho do código: } & $4,5 \mathrm{~cm}^{2}$ \\
\hline Responsáveis: & \multicolumn{4}{|c|}{ Aline Bezerra da Costa e Sandro Rodrigues de Souza } \\
\hline Proposta inicial: & \multicolumn{4}{|c|}{$\begin{array}{l}\text { Analisar o tamanho e o posicionamento do código nas embalagens; } \\
\text { Desenvoltura do usuário com os produtos; Posicionamento de leitura; Teste do } \\
\text { Mecanismo de abertura do aplicativo por movimento; Validação do aviso de } \\
\text { "câmera disponível" - acelerômetro. }\end{array}$} \\
\hline \multirow[t]{2}{*}{ Avaliação: } & \multicolumn{2}{|l|}{ Pontos fortes } & \multicolumn{2}{|c|}{ Pontos fracos } \\
\hline & \multicolumn{2}{|c|}{$\begin{array}{l}\text { - Leitura eficaz dos códigos nos } \\
\text { produtos e embalagens escolhidos; } \\
\text { - Aplicação da proposta se mostrou } \\
\text { viável; } \\
\text { - Desenvoltura do usuário. }\end{array}$} & \multicolumn{2}{|c|}{$\begin{array}{l}\text { - Dificuldade na leitura dos códigos } \\
\text { em garrafas de vidro de material } \\
\text { claro/translúcido - reflexo interferiu na } \\
\text { leitura da câmera; } \\
\text { - Manuseio do aparelho smartphone } \\
\text { pelo usuário. }\end{array}$} \\
\hline Resultado: & \multicolumn{4}{|c|}{$\begin{array}{l}\text { Necessidade de adequação: } \\
\text { - Resposta ao usuário assim que a câmera estiver disponível - em áudio; } \\
\text { - Acionamento do flash da câmera para controle de luminosidade do } \\
\text { ambiente. }\end{array}$} \\
\hline
\end{tabular}

Efetuou-se um terceiro plano de teste (Tabela 4) no qual foi realizada a instalação do aplicativo no Smartphone do usuário. O usuário mostrou-se muito satisfeito com 0 resultado obtido na identificação e externalização através de áudio, possibilitando ouvir o nome do produto escaneado.

Tabela 4 - Plano de Teste - Teste 3.

\begin{tabular}{|c|c|c|c|c|c|}
\hline Teste: & Tipo: & Aplica & ção2 & Data: & $14 / 06 / 2018$ \\
\hline Testador: & Usuário final & & Amb & Teste: & Residência \\
\hline Equipamento: & \multicolumn{5}{|c|}{ Smartphone do usuário } \\
\hline $\begin{array}{l}\text { Material } \\
\text { impresso: }\end{array}$ & \multicolumn{2}{|l|}{ Folha sulfite } & \multicolumn{2}{|c|}{ Tipo de impressão: } & Laser \\
\hline Base de análise: & \multicolumn{2}{|c|}{$\begin{array}{l}\text { Folha sulfite cortada no } \\
\text { formato de etiquetas, sendo } \\
\text { estas fixadas nos produtos: } \\
\text { embalagem de farinha de } \\
\text { frutas e garradas de licor } \\
\text { (vidro) }\end{array}$} & \multicolumn{2}{|c|}{ Tamanho do código: } & $2,5 \mathrm{~cm}^{2}$ \\
\hline Responsáveis: & \multicolumn{5}{|c|}{ Aline Bezerra da Costa e Sandro Rodrigues de Souza } \\
\hline Proposta inicial: & \multicolumn{5}{|c|}{$\begin{array}{l}\text { Instalação dos aplicativos no equipamento do usuário; Teste do ambiente de } \\
\text { uso; Treinamento do uso do equipamento; Validação da confirmação de "leitura } \\
\text { disponível" através de áudio. }\end{array}$} \\
\hline
\end{tabular}




\begin{tabular}{|c|c|c|}
\hline \multirow[t]{2}{*}{ Avaliação: } & Pontos fortes & Pontos fracos \\
\hline & $\begin{array}{l}\text { - Validação: } \\
\text { - Acionamento do aplicativo por } \\
\text { movimento; } \\
\text { - Confirmação em áudio de que } \\
\text { a câmera está disponível; } \\
\text { - Aplicação do aplicativo. }\end{array}$ & $\begin{array}{l}\text { - Dificuldade de leitura em ambiente } \\
\text { com baixa luminosidade; } \\
\text { - Código grande - interferência na } \\
\text { captação da imagem (outros códigos); }\end{array}$ \\
\hline Resultado: & \multicolumn{2}{|c|}{$\begin{array}{l}\text { Necessidade de adequação: } \\
\text { - Delay de leitura de imagem; } \\
\text { - Acionamento do flash da câmera para controle de luminosidade do } \\
\text { ambiente. }\end{array}$} \\
\hline
\end{tabular}

Foram utilizados três tamanhos diferentes de $Q R$ Code, conforme Figura 8, sendo

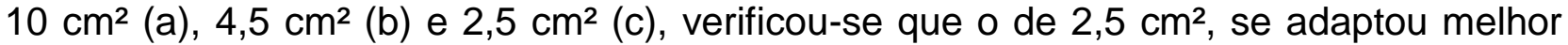
nas embalagens, também foi testado o nível de luminosidade do ambiente, percebeu-se que o aplicativo tinha certa tolerância à luminosidade, quanto maior ou menor essa luminosidade, maior era a dificuldade de se obter uma leitura do aplicativo, para resolver esse problema seria necessário o ajuste automático da câmera ou a mudança do ambiente.
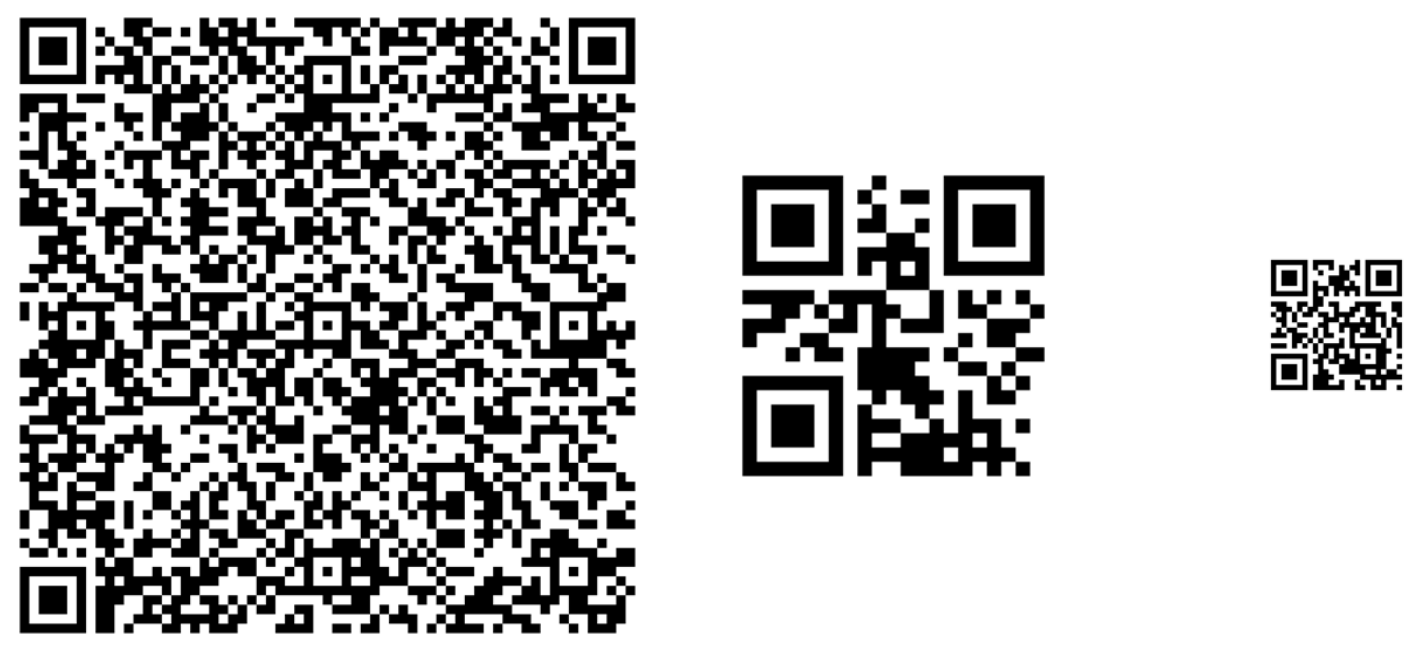
a) Texto sobre a Bocaiuva - 10X10 $\mathrm{cm}^{2}$
b) Licor de Guavira $-4,5 \times 4,5 \mathrm{~cm}^{2}$
c) Farinha de Bocaiúva $-2,5 \times 2,5 \mathrm{~cm}^{2}$

Figura 8: Códigos QR para teste.

Além disso, foram realizados os testes em diversas superfícies, tais como retas, côncavas e ásperas, onde se obteve melhores resultados nas superfícies planas. Outro item levado em consideração foi qual seria a melhor forma de se ter bons resultados, uma etiqueta fixada no produto ou uma etiqueta que pudesse ser manuseada pelo 
usuário e anexada (amarrada) ao produto em questão. Objetivando maior praticidade no manuseio pelo usuário, definiu-se a etiqueta fixada na embalagem, haja vista a possibilidade de impressão em rótulos e embalagens.

Ao utilizar os códigos em uma garrafa de vidro de material mais escuro (marrom) a leitura do código foi realizada mais facilmente pelo usuário final. No caso de uma garrafa do mesmo material, porém na cor translúcida, por conta do reflexo do vidro, o aplicativo teve mais dificuldade em realizar a leitura.

\section{CONCLUSÃO}

O desenvolvimento do trabalho permitiu que conhecêssemos a fundo às dificuldades e desafios a serem enfrentados durante o desenvolvimento de um produto de software. No produto em questão o modelo de Prototipação foi uma assertiva que permitiu que ordenássemos nossos trabalhos da melhor maneira. As funcionalidades básicas puderam ser atendidas, porém muitas outras foram identificadas durante todo 0 processo.

A prototipação, com envolvimento do cliente para o levantamento de requisitos, com certeza foi um dos maiores desafios, até mesmo devido à delicadeza da situação e todo o cuidado com o usuário.

Sobretudo, foi possível desenvolver o aplicativo SpeakCode, capaz de fazer a leitura de uma mensagem codificada em $Q R$ Code, e a respectiva transcrição em áudio desse conteúdo. Dessa maneira, é possível que pessoas com deficiência visual, possam através do uso desta tecnologia etiquetar produtos diversos, de uso diário ou específico, tais como: frascos e embalagens de difícil identificação, cabides de roupas, tipo de um produto alimentício (bolacha de chocolate, iogurte de morango), entre diversos usos a serem moldados conforme as especificidades de cada usuário.

O uso dessa tecnologia poderá atender a um público diverso, haja vista a baixa complexidade dos processos. Sendo que o código pode ser criado em diversos websites e impresso em papel sulfite. Assim, pensando na acessibilidade dos deficientes visuais acredita-se que esse sistema pode oferecer ao usuário informações importantes, como o nome ou a validade de um produto, também poderá ser realizada a leitura de um livro, entre outros benefícios.

No entanto, pôde-se identificar, que há a necessidade de se rever a utilização do $Q R$ Code, até então, comum em embalagens, cartazes, de maneira a otimizar o seu uso, proporcionando maior utilidade a essa tecnologia, não somente direcionar para uma página da internet, o que pode ser facilmente feito por uma pessoa de boa visão, mas que estes possam reproduzir uma breve descrição do item, o que auxiliaria na acessibilidade dos deficientes visuais.

Posteriormente poderão ser implantadas as seguintes funcionalidades:

a) Gerador $Q R$ Code;

b) Manual do Usuário;

c) Armazenamento em banco de $Q R$ Code pessoal; 
d) Compartilhamento de $Q R$ Code;

e) Acionamento do flash da câmera para tratar a ausência de luminosidade do ambiente.

f) Maior distância de alcance da câmera, utilizando um sistema de câmera integrado a um equipamento de Arduino ou Raspberry, através da tecnologia de visão computacional.

Contudo, assim como foi obtida uma boa avaliação pelo usuário, acreditamos que é possível obter soluções tecnológicas para atender outras demandas de tecnologias assistivas a partir da experiência aqui vivenciada.

\section{REFERÊNCIAS}

BRASIL. Decreto no 3.298, de 20 de dezembro de 1999. Regulamenta a Lei no 7.853, de 24 de outubro de 1989, dispõe sobre a Política Nacional para a Integração da Pessoa Portadora de Deficiência, consolida as normas de proteção, e dá outras providências. Brasília, 20 dez. $1999 . \quad$ Disponível em: <http://www.planalto.gov.br/ccivil_03/decreto/d3298.htm>. Acesso em: Acesso em: 18 nov. 2019.

BRASIL. Decreto no 6.949, de 25 de agosto de 2009. Promulga a Convenção Internacional sobre os Direitos das Pessoas com Deficiência e seu Protocolo Facultativo, assinados em Nova York, em 30 de março de 2007. Brasília, 25 ago. 2009. Disponível em: <http://www.planalto.gov.br/ccivil_03/_ato2007-2010/2009/decreto/d6949.htm>. Acesso em: Acesso em: 18 nov. 2019.

BRASIL. Lei $n^{\circ}$ 10.098, de 19 de dezembro de 2000. Estabelece normas gerais e critérios básicos para a promoção da acessibilidade das pessoas portadoras de deficiência ou com mobilidade reduzida, e dá outras providências. Disponível em: <http://www.planalto.gov.br/ccivil_03/leis/L10098.htm>. Acesso em 18 nov. 2019.

CAMPÊLO, Robson A. et al. Inclusão digital de Deficientes Visuais: 0 uso da Tecnologia Assistiva em Redes Sociais online e Celulares. 2011. 107 p.- Faculdade de Filosofia, Ciências e Letras de Caruaru, Instituto Federal de Pernambuco (IFPE), Belo Jardim, $2012 . \quad 1 . \quad$ Disponível em: <https://siaiap32.univali.br/seer/index.php/acotb/article/view/6329>. Acesso em: 04 fev. 2020.

DENSO WAVE. What is a QR Code? Disponível em: <https://www.densowave.com/en/adcd/fundamental/2dcode/qrc/index.html>. Acesso em 04 mar. 2019.

ENGHOLM, Hélio Júnior. Engenharia de Software: Na prática. São Paulo: Novatec Editora, 2010.

ERICKSON, F. Ethnographic Microanalysis. In: MCKAY, S.L. \& HORNBERGER, N.H. Sociolinguistics and Language Teaching. Cambridge: Cambridge University Press, $p$. 283-306, 1986. 
FUNDAÇÃO DORINA NOWILL. Tecnologia Assistiva. São Paulo, 2017. Disponível em: $<$ https://www.fundacaodorina.org.br/a-fundacao/deficiencia-visual/tecnologia-assistiva/>. Acesso em: 22 abr. 2019.

HARA, Masahiro et. al. Masahiro Hara et al - the QR code. 2014. (4m58s) Disponível em: <https://www.youtube.com/watch?v=ZLhoBWlrTtw>. Acesso em: 27 fev. 2020.

ISO. ISO/IEC 18004:2006. Information technology - Automatic identification and data capture techniques - QR Code 2005 bar code symbology specification. 2006. Disponível em: <https://www.iso.org/standard/43655.html>. Acesso em: 04 fev. 2020.

KIMURA, Karin Therumi. Formatos de Codificação da Linguagem - o caso do QR Code. 2014. 52 p. Trabalho de Conclusão de Curso (Especialização). Escola de Comunicações e Artes da Universidade de São Paulo. São Paulo, 2014.

LIAO, K. e LEE, W. A novel user authentication scheme based on $Q R$ Code. Journal of networks, 2010.

MAIOLA, Carolina dos Santos; SILVEIRA, Tatiana dos Santos da. Deficiência Visual. Indaial: Grupo UNIASSELVI, 2009.

MARTINS, Augusto Passalaqua. QR Color Code: Uma nova metodologia para armazenamento de grandes volumes de dados em meio impresso. 2009. $138 \mathrm{p}$. Monografia (Ciência da Computação) - Instituto de Ciências Exatas, Universidade de Brasília, Brasília, 2009.

MENG, Michael; STEINHARDT, Stephanie; SCHUBERT, Andreas. Application Programming Interface Documentation: What Do Software Developers Want? Journal of Technical Writing and Communication. 2018.

MONTEIRO, J. L. Os desafios dos cegos nos espaços socias: Um olhar sobre a acessibilidade. 2012 Disponível em: <http://www.ucs.br/etc/conferencias/index.php/anpedsul/9anpedsul/paper/viewFile/1081/ 649>. Acesso em 18 jun. 2019.

NAÇÕES UNIDAS NO BRASIL. OMS afirma que existem 39 milhões de cegos no mundo. 2013. Disponível em: <https://nacoesunidas.org/oms-afirma-que-existem-39milhoes-de-cegos-no-mundo/>. Acesso em 18 jun. 2019.

PFLEEGER, Shari Lawrence. Engenharia de Software: Teoria e Prática. $2^{a}$ ed. São Paulo: Prentice Hall, 2004.

SOON, Tan Jin. $\boldsymbol{Q R}$ Code. Synthesis Journal, 2008. Disponível em: $<$ https://foxdesignsstudio.com/uploads/pdf/Three_QR_Code.pdf >. Acesso em jul. 2019.

VILLELA, Flávia. 6,2\% da população têm algum tipo de deficiência, 2015. Agência Brasil. Disponível em: <http://www.ebc.com.br/noticias/2015/08/ibge-62-da-populacaotem-algum-tipo-de-deficiencia>. Acesso em: 15 jun. 2019. 